\title{
Mundmotorische Übungen für Kinder mit Lippen- Kiefer-Gaumensegel-Spalten
}

\author{
Patienteninformation
}

Eltern von Kindern mit Lippen-Kiefer-Gaumensegel-(LKGS-)Spalten begleiten ihre Kinder von Beginn an zu verschiedenen Behandlungen. Die logopädische Intervention ist eine davon, da es bereits im Säuglingsalter zu Saug- und Fütterstörungen kommen kann und im Verlauf Probleme in der Aussprache, z.B. Fehlartikulationen der SLaute oder ein Näseln, auftreten können. Kompensatorische Störungen entstehen, wenn das Kind Mechanismen für eine bessere Verständlichkeit einsetzt. Strukturelle Auffälligkeiten bei LKGS-Spalten werden in Deutschland frühzeitig operativ versorgt. Dennoch bleiben Vernarbungen, die zu Einschränkungen beim Essen und/oder Sprechen führen können.

Im Folgenden sind einige Übungen aufgeführt, durch die sie ihr Kind unterstützen können. Achten Sie darauf, dass Ihr Kind dabei in einer aufrechten Position sitzt. Um eine Veränderung in der Muskulatur zu erzielen, sollten nur wenige Übungen möglichst täglich wiederholt werden. Dabei beträgt eine Übungseinheit max. 10 Minuten. Zur Motivation können Sie die Durchführungen mit Reimen, Abzählversen oder Liedern begleiten oder die Übungen in eine Geschichte einbinden. Ihrem Einfallsreichtum und dem Ihres Kindes sind dabei keine Grenzen gesetzt!

\section{Für die Lippen}

"Lippenmassage“: Mit den Zeigefingern wird die Oberlippe von der Nase zum Lippenrot nach unten ausgestrichen.

Ziel: passive und sanfte Dehnung der Oberlippe und evtl. Narbengewebe

Umsetzung: z.B. morgens und abends beim Eincremen des Gesichtes.

"Uroma-Sprache“: Die Lippen schließen sich um die Zahnreihen nach innen, so dass kein Lippenrot mehr zu sehen ist.

Ziel: aktive Dehnung der Lippenmuskulatur und evtl. Narbengewebe.

Umsetzung: z.B. Lippen spielen verstecken. Es kann mit eingezogenen Lippen gesprochen werden, wie die Uroma ohne Zähne spricht.
Übungsregeln

- aufrechte Sitz- und Kopfhaltung

- viele Wiederholungen

- motivierende Gestaltung

- feste Zeitfenster einplanen

- vormachen und mitmachen

- Überforderung vermeiden

„Kussmund“ und „Lachmund“: Die Lippen werden geschlossen spitz nach vorn gestreckt und breit gezogen.

Ziel: Kräftigung der Lippen- und Wangenmuskulatur.

Umsetzung: z.B. dem Teddy oder den Eltern werden Küsschen gegeben, „Fotografieren“ spielen und dabei lächeln.

\section{Fürr die Zunge}

„Kompass“: Die Zunge tippt bei offenem Mund in Richtung Nase, Kinn und Mundwinkel und bleibt dort 1-3 Sekunden. Ziel: Förderung der Lateralbewegung, sowie Bewegung nach oben und unten, Gaumensegeldehnung.

Umsetzung: z. B. mit dem Spruch „Im Osten geht die Sonne auf, im Süden ist ihr Mittagslauf, im Westen wird sie untergehen im Norden ist sie nie zu sehen“.

„Zähneputzen“: Die Zunge fährt bei offenen Lippen erst oben dann unten außen an den Zahnreihen entlang.

Ziel: Kräftigung der Zungenmuskulatur, Verbesserung des Bewegungsumfangs und der Bewegungsgenauigkeit, Gaumensegeldehnung.

Umsetzung: z.B. die Zunge spielt Zahnbürste und putzt jeden Zahn.

\section{Für das Gaumensegel}

"Luftballon“: die Wangen werden aufgeblasen und halten die Luft im Mund Ziel: Dehnung der Wangenmuskulatur, Förderung des Mundschlusses, Kräftigung des Gaumensegels.

Umsetzung: Wangen aufblasen und mit den Händen platzen lassen.

„Staubsauger": mit einem Strohhalm ansaugen.
Ziel: Erzeugen und Halten eines Unterdrucks im Mundraum, Anhebung des Gaumensegels, Lippenschluss.

Umsetzung: z. B. kleine leichte Gegenstände (Papierschnipsel $1 \mathrm{~cm}^{2}$ ) wie ein Kran vom Tisch in eine Schachtel heben.

„Wind": durch das Spitzen der Lippen wird der Luftstrom gelenkt, Pusten.

Ziel: Gaumensegelhebung, Lippenkräftigung.

Umsetzung: verschiedene leichte Gegenstände (Wattebausch, Federn, Seifenblasen) werden z.B. in ein Tor gepustet oder in der Luft gehalten.

\section{Zur Förderung der Sensibilität}

„Schatzsuche“: Thermische Reize setzen Ziel: Verbesserung der Reizwahrnehmung und -lokalisation.

Umsetzung: Lippen, Zunge, Wangen und Gaumen mit einem eisgekühlten Wattestäbchen kurz berühren. Das Kind soll den angetippten Ort mit dem Finger oder der Zunge zeigen.

„Blinde Kuh“: Formen im Mund erkennen Ziel: Verbesserung der räumlichen Wahrnehmung im Mundraum.

Umsetzung: Dem Kind werden verschiedene Formen (Nudeln oder geschnitzte Möhren) gezeigt und anschließend „geheim" auf die Zunge gelegt. Es soll nun die Form im Mund erfühlen.

\section{Fazit}

Im Alltag können Eltern von Kindern mit LKGS-Spalten die Beweglichkeit, Sensibilität und die Narbenheilung unterstützen. Hierbei kommt es vor allem auf regelmäßiges Üben und die Mitarbeit des Kindes an.

\section{Magrit Schröder, Wenke Walther,} Hannover

überreicht durch Thieme und 